\title{
Methodological implications of interaural correlation: Count heads not ears
}

\author{
STANLEY COREN and A. RALPH HAKSTIAN \\ University of British Columbia, Vancouver, British Columbia, Canada
}

\begin{abstract}
In a sample of 425 subjects, pure-tone hearing thresholds between the right and left ears were shown to have an average correlation of .885 (or .783 with age partialed out). This high interaural correlation is shown to invalidate the experimental procedure of entering data on the basis of "ears," where each subject can contribute one or two audiograms to the data pool, since such aggregation is demonstrated to produce spuriously high levels of apparent statistical significance in inferential statistical tests.
\end{abstract}

The custom of using, as the unit of analysis, results from individual ears in the statistical analyses of grouped data from hearing tests (e.g., testing 60 subjects but conducting the analyses on 120 ears) has a long history. The vast majority of the early studies that attempted to assess the efficiency of limited-frequency testing for auditory sensitivity and screening used individual ears in this manner (e.g., Lightfoot, Buckingham, \& Kelly, 1959; Maxwell \& Davidson, 1961; Norton \& Lux, 1960; Ventry \& Newby, 1959). This practice has continued into the contemporary literature and is found in many published reports in some of the best journals in hearing research. For example, studies by Markides (1980), Verschuure, van den Wijngaart, Brocaar, and Nagels (1985), and Wiley, Oviatt, and Block (1987) are an informal sampling of studies containing such usage within the last few years; many others could be added to this list. The convention of treating each ear's threshold pattern or audiogram as if it were a separate observation, despite the fact that pairs of them may have come from the same individuals, is, however, statistically justifiable only under certain very restrictive and unlikely conditions.

The use of the measurements obtained from the two ears of a particular subject as though they were independent observations can be justified only if there is statistical independence between the thresholds of the two ears. This means that there should be no correlation between the hearing-level thresholds of the right and left ears of individuals. If there is such correlation, then the practice of including scores from both ears mixes independent observations (between individuals) with dependent observations (taken from the same individual), leading to the

\footnotetext{
This research was supported in part by grants from the British Columbia Health Care Research Foundation and the Natural Sciences and Engineering Research Council of Canada. The author would like to acknowledge the assistance of Wayne Wong, Joan Donelly, Geof Donelly, and Dereck Atha, who assisted in the collection of these data. Requests for reprints should be addressed to Stanley Coren, Department of Psychology, University of British Columbia, 2136 West Mall, Vancouver, British Columbia V6T 1Y7, Canada.
}

possibility that statements of statistical significance resulting from such a procedure may be erroneous.

This situation is similar to that encountered in studies of visual acuity measures. In much the same way that hearing researchers seem to assume implicitly that the hearing levels of the two ears are independent, vision researchers, too, have tended to view the acuity of each eye as if it were separate and uncorrelated with its contralateral counterpart. It has now been demonstrated that there is a high degree of similarity between the eyes, with the average correlation between the measured acuity of the two eyes being approximately .81 , depending upon the measures used (Coren, 1987). In a study concerned with the interrelationship among various measures of puretone threshold, Coren (1989) cautioned that a similar situation might exist in the realm of audition. Certainly, the existing literature has suggested a number of factors that could produce a correlation between the hearing-level thresholds of the right and left ears of any given individual. The effects, for example, of aging and environmental exposure to noise, are known to be linked to threshold sensitivities within particular frequency ranges (see Corso, 1981, or Kryter, 1985, for general reviews). Such factors would certainly affect both ears for any designated subject.

In light of the above considerations and of the prevalence of the convention of employing measurements from pairs of ears as if they were independent, it is methodologically important to establish empirically whether or not there is a correlation between audiological sensitivities of the two ears. Such a nonzero correlation, if present, would seriously undermine the validity of the custom of pooling, into a single data set, the observed scores obtained from both ears of subjects. The following study was conducted to provide illumination on this issue.

\section{METHOD}

\section{Subjects}

A sample of 425 subjects (249 females and 176 males), who responded to advertisements in a university population and in the general community, augmented by direct solicitation in several 
seniors groups, was used. The subjects ranged in age from 17 to 92 years, with a mean age of 28.1 years and standard deviation of 19.6 .

\section{Procedure}

All subjects were tested individually in a sound-deadened room. A MAICO (MA-24) audiometer was used to obtain pure-tone, airconduction hearing thresholds for six test frequencies: 250,500 , $1000,2000,4000$, and $8000 \mathrm{~Hz}$. Each ear was tested separately. The method of limits was used with 5-dB SPL steps. For each test frequency, a descending series was used to approximately locate the threshold; then three determinations of threshold were taken for each tone using ascending series. The median of the three measures served as an estimate of threshold sensitivity for that ear.

\section{RESULTS AND DISCUSSION}

A broad range of pure-tone threshold ability was demonstrated in this heterogeneous sample, with averaged hearing thresholds across the six test frequencies ranging from a minimum of $-0.42 \mathrm{~dB}$ to a maximum of $98.6 \mathrm{~dB}$. When the average threshold was used (as recommended by Coren, 1989), there were no significant differences between males and females in this sample, so the data were collapsed across gender.

To determine the relationship between the hearing-level thresholds for the two ears, product-moment correlations were computed. This was done by pairing the pure-tone threshold for each ear with the corresponding threshold for the contralateral ear for each subject at each test frequency. The resultant values appear in the left column of Table 1.

As can be seen from Table 1, the hypothesis of no correlation between the two monaural sensitivities is not supported. Instead, we find extremely high levels of correlation between the hearing-level thresholds for the two ears, at all test frequencies. All of these correlations are highly significant, with $p$ values much less than .001 . The tabled correlations between the left and right ears average .885 . If we take the overall average hearing-level threshold for the six test frequencies for each ear (which Coren, 1989, proposed as a reliable and valid composite index of hearing sensitivity), we find that the correlation between left and right ears rises to the extremely high value of .953 .

There is an important need for caution here. Since hearing sensitivity diminishes with age, given the broad age range that we have employed here, the question arises as to whether we have observed a high interaural correlation in this study solely because of the age effect, that is, with no correlation between ear thresholds for subjects of identical age. The most accurate and comprehensive way to test this possibility is to examine the interaural correlation with the effects of age partialed out. This was done, and the results are given in Table 1 . As can be seen, the correlations are still all high, averaging .783 (all with $p<.001$ ), even though age has been statistically held constant. The partial correlation between the overall average across the six frequencies for the right and left ears is very high -.887 .

As an alternate means of demonstrating that the interaural correlation is not an artifact of bilateral hearing loss with age, the sample was partitioned and only subjects aged 30 years or less were considered. Using the six frequency average for each ear, we find an interaural correlation of $.803(p<.001)$. Thus, the correlation between the thresholds of the two ears represents not a simple artifact of age-related hearing loss, but a stable finding, even for relatively homogeneous age samples.

The correlations between the two ears are almost as high as the correlations between successive measures taken on the same ear on separate occasions (e.g., the reliability of measurement). Some typical evidence of audiometric reliability appears in the right half of Table 1 . The High and Gallo (1963) results reported in the table are somewhat lower than those of Brown (1948), but represent the mean of six testing occasions per ear. If we average the two sets of same-ear, test-retest correlations, the Brown

Table 1

Correlations Between Pure-Tone Hearing Thresholds for the Right and Left Ears, by Test Frequency, and Test-Retest Correlations (Same Ear) Obtained by Other Authors

\begin{tabular}{|c|c|c|c|c|}
\hline \multirow[b]{3}{*}{$\begin{array}{l}\text { Pure-Tone } \\
\text { Test Frequency }(\mathrm{Hz})\end{array}$} & \multicolumn{2}{|c|}{$\begin{array}{l}\text { Right- vs. Left- } \\
\text { Ear Thresholds }\end{array}$} & \multirow{2}{*}{\multicolumn{2}{|c|}{$\begin{array}{l}\text { Test-Retest Correlations } \\
\text { (Same Ear) }\end{array}$}} \\
\hline & \multicolumn{2}{|c|}{$\begin{array}{l}\text { Present Study } \\
\quad(n=425) \\
\end{array}$} & & \\
\hline & $\begin{array}{l}\text { Pearson } \\
\text { Correlation }\end{array}$ & $\begin{array}{c}\text { Age } \\
\text { Partialed }\end{array}$ & $\begin{array}{c}\text { Brown }(1948)^{*} \\
(n=60 \text { ears })\end{array}$ & $\begin{array}{l}\text { High \& Gallo (1963)† } \\
(n=444, \text { right ear })\end{array}$ \\
\hline 250 & .788 & .743 & .93 & - \\
\hline 500 & .823 & .772 & .95 & .60 \\
\hline 1000 & .858 & .801 & .91 & .70 \\
\hline 2000 & .920 & .832 & .94 & .81 \\
\hline 4000 & .931 & .808 & .95 & .89 \\
\hline 8000 & .923 & .743 & .74 & - \\
\hline $\begin{array}{l}\text { Overall mean } \\
\text { threshold for ear }\end{array}$ & .953 & .887 & & \\
\hline
\end{tabular}

*Test frequencies in Brown (1948) differ slightly from those tabled, since he actually employed octaves starting with $256 \mathrm{~Hz}$ rather than the usual $250 \mathrm{~Hz}$. †These are mean test-retest correlations over six occasions (hence the means of 15 interoccasion correlations). 
Table 2

Standard Deviations of Difference Scores (sDiff) for the Present Study of Left- and Right-Ear Thresholds and for Earlier Test-Retest (Same Ear) Studies

\begin{tabular}{|c|c|c|c|c|}
\hline \multirow[b]{3}{*}{$\begin{array}{c}\text { Pure Tone } \\
\text { Test Frequency }(\mathrm{Hz}) \\
\end{array}$} & \multicolumn{4}{|c|}{ Standard Deviations of Difference Scores, sDiff } \\
\hline & \multirow{2}{*}{$\begin{array}{l}\text { Right-vs.Left- } \\
\text { Ear Thresholds } \\
\text { Present Study }\end{array}$} & \multicolumn{2}{|c|}{$\begin{array}{l}\text { Test-Retest Studies } \\
\text { (Same Ear) }\end{array}$} & \multirow{2}{*}{$\begin{array}{l}\text { Expected hac } \\
\text { Separate-Ear } \\
\text { Scores been } \\
\text { Independent }\end{array}$} \\
\hline & & $\begin{array}{l}\text { Brown } \\
(1948)\end{array}$ & $\begin{array}{c}\text { High \& Gallo } \\
(1963)\end{array}$ & \\
\hline 250 & 8.34 & 6.57 & - & 18.10 \\
\hline 500 & 7.41 & 5.97 & 7.79 & 17.60 \\
\hline 1000 & 7.38 & 6.95 & 8.83 & 19.37 \\
\hline 2000 & 7.01 & 6.52 & 8.76 & 24.68 \\
\hline 4000 & 8.25 & 6.15 & 11.40 & 31.27 \\
\hline 8000 & 10.99 & 9.93 & - & 22.52 \\
\hline \multicolumn{5}{|l|}{ Overall Mean } \\
\hline Threshold for Ear & 4.89 & & & 22.52 \\
\hline \multicolumn{5}{|l|}{ Means Over } \\
\hline Frequencies Tabled & 8.23 & 7.02 & 9.20 & 25.08 \\
\hline
\end{tabular}

Note-The estimated sDiff values for the present study had the separate-ear scores actually been independent (uncorrelated) are also provided.

results average .920 and the High and Gallo correlations average .773. All averaging of correlations, incidentally, was done in conjunction with the Fisher $r$-to- $z$ transformation (see, e.g., Glass \& Hopkins, 1984, pp. 304-305). Thus, the average for the present between-ear correlations falls clearly into the correlation range defined by the reliability of audiometric measurement.

To show the effects of the interaural correlation more clearly, we present, in Table 2, results obtained by calculating the standard deviation of difference scores for right-ear-sensitivities minus left-ear-threshold sensitivities at the various test frequencies used in the present study. In addition, we calculated what the standard deviation of difference scores would have been had the individual ear scores been independent. We performed the same calculations on the test-retest data of Brown (1948) and High and Gallo (1963), used earlier, for comparative purposes (the latter based upon the $\sigma_{\text {Diff }}$ for the first and second testing only, to be more comparable to Brown's data). These computations are easily made using the reported single-occasion standard deviations and the interoccasion correlations. The obtained $\sigma_{\text {Diff }}$ values for the present data, involving a comparison of the left and right ears, are very similar in magnitude to those obtained when one simply retests the same ear. The expected magnitude of the $\sigma_{\text {Diff }}$ values had we assumed independence of right- and left-ear sensitivities are predictably much greater (average of 25.08) than the actually obtained average $\sigma_{\text {Diff }}(8.23)$.

We can thus summarize the data presented in Tables 1 and 2 by suggesting that audiological researchers can expect no more deviation between pure-tone thresholds taken from the left and right ears of one individual than would be found if one took a pair of measurements on the very same ear on two separate occasions. It should be clear that treating individual-ear scores as though they were independent measures is strongly at odds with the reality of the data. Inferential procedures that assume in- dependence of observations will therefore be in error if applied to such data. We outline the nature of this error in the next section.

\section{STATISTICAL IMPLICATIONS}

The methodological implications of the preceding results are important. It is clear from the data that we have analyzed here that the practice of using pairs of individualear scores as though they were independent is invalidated by the strong correlation observed between the thresholds of the left and right ears. The effects of this slippage between assumption and reality needs to be spelled out so that researchers can reevaluate data that may have been subject to this particular methodological error.

First, it is important to note here that the actual values for means, variances, and correlation coefficients calculated from data distributions in which one has violated the assumption of independence by recording two separate measurements (ears) per individual may not themselves be in error. Thus, a study in which a procedure such as factor analysis, principal components analysis, or curve fitting, for example, is used in a purely descriptive, noninferential, way will, in all likelihood, be free of the particular error we are describing here. What will be incorrect will be the estimates of the standard errors of the means, variances, or correlation coefficients. Since inferential tests are based upon these standard errors, such tests of statistical significance will also be incorrect.

To make this point clearer, we can take the data from the present study reported in Tables 1 and 2, and analyze them in two ways. The first, which we will label "incorrect," is the method, often used in the past, in which each single-ear score is treated as an independent observation. In the present analysis, given our $\mathbf{4 2 5}$ subjects, this procedure results in a sample size of 850 "ears" as observation units. There are several possible "correct" models to which these results may be compared. The most obvi- 
ous one (if results from both ears are to be used) involves simply averaging the single-ear scores from any given individual. In the present analysis, this procedure results in a sample size of 425 subjects, or ear-pairs.

The means are computed for each measure, and a .95 confidence interval is set around the mean. In this application, Type I error results when an interval fails to capture the parameter (the actual mean of the population). Here we have set the probability of Type I error (the "level of significance") to .05 . Since we can compute the correct confidence interval using a statistical model in which the assumption of independence is met, we can also assess the actual degree of Type I error attached to the intervals obtained by the incorrect procedure.

Although the means are the same for both methods, the standard errors of the means, upon which confidence intervals and other inferential statistics are based, are smaller under the incorrect model (recording individual ears as though independent). The effect of this discrepancy on the degree of Type I error is quite pronounced. Under the incorrect model, although the presumed probability of error in rejecting the null hypothesis is reported as the conventional $5 \%$ ( 1 out of 20 ), in fact, it is actually in the $14 \%$ to $16 \%$ range ( 1 out of 7 ), given the levels of interaural correlation that we have observed in the data presented here. This will be true for procedures such as the $t$ test and analysis of variance, and all inferential significance tests conducted in connection with variances and correlation coefficients. Thus, in all inferential applications, the effect of treating the ears as if they were independent will be to increase the tendency to suggest statistical significance where it is not truly present.

Although all of the preceding leaves us with something of a problem in evaluating the results of previous studies that have employed the practice of treating the measurements from individual ears as independent observations, the practical implications for future experimental work seem straightforward. Researchers can select the "better ear" or the " poorer ear," depending upon whether their interests lie in questions of optimal performance or maximal deficit. Alternatively, only the right or the left ears of subjects may be used, or, for the subject's comfort, the "preferred" or "dominant" ear (cf. Porac \& Coren, 1981) may be selected. Given the high interear correlation noted in the present paper, it may make most sense to sum or average the thresholds across the two ears for each individual in order to obtain a single number that is representative of that person's pure-tone-threshold sensitivity. Whichever of these alternatives we decide upon, however, the central point demonstrated here is that we must count, and record as observational units, heads, not ears.

\section{REFERENCES}

Brown, R. E. C. (1948). Experimental studies on the reliability of audiometry. Journal of Laryngology \& Otology, 62, 487-524.

COREN, S. (1987). Reporting the visual acuity of groups: The relationship among alternate measures. American Journal of Optometry \& Physiological Optics, 64, 897-900.

COREN, S. (1989). Summarizing pure-tone hearing thresholds: The equipollence of components of the audiogram. Bulletin of the Psychonomic Society, 27, 42-44.

Corso, J. F. (1981). Aging sensory systems and perception. New York: Praeger.

GLAss, G. V., \& Hopkins, K. D. (1984). Statistical methods in education and psychology (2nd ed.). Englewood Cliffs, NJ: Prentice-Hall.

High, W. S., \& Gallo, R. P. (1963). Audiometric reliability in an industrial hearing conservation program. Journal of Auditory Research, 3, 15-34.

KRYTER, K. D. (1985). The effects of noise on man (2nd ed.). Orlando, FL: Academic Press.

Lightfoot, C., Buckingham, R. A., \& Kelly, M. N. (1959). A check on Oto-Chek. A.M.A. Archives of Otolaryngology, 70, 103-112.

MarkIDES, A. (1980). The relation between hearing loss for pure tones and hearing loss for speech among hearing-impaired children. British Journal of Audiology, 14, 115-121.

MaXWELl, R. W., \& DAvidson, G. D. (1961). Limited-frequency screening and ear pathology. Joumal of Speech \& Hearing Disorders, 26, 122-125

NorTon, M. C., \& Lux, E. (1960). Double-frequency auditory screening in public schools. Journal of Speech \& Hearing Disorders, 25, 293-299.

Porac, C., \& Coren, S. (1981). Lateral preferences and human behavior. New York: Springer-Verlag.

Ventry, I. M., NeWBY, H. A. (1959). Validity of the on-frequency screening principle for public school children. Journal of Speech \& Hearing Research, 2, 147-151.

VerschuUre, J., Van den Wungaart, W. S. I. M., Brocaar, M. P., \& NAGELS, M. M. (1985). Methods of analysis of large numbers of audiograms. Audiology, 24, 2-14.

Wiley, T. L., Oviatt, D. L., \& Block, M. G. (1987). Acousticimmittance measures in normal ears. Journal of Speech \& Hearing Research, 30, 161-170.

(Manuscript received November 13, 1989; revision accepted for publication April 17, 1990.) 